\title{
Cell behavior under hypoxic conditions. 3D computational model
}

\author{
Pau Urdeitx ${ }^{1}$, S. Jamaleddin Mousavi ${ }^{1}$, Mohamed H. Doweidar*1 \\ ${ }^{1}$ Mechanical Engineering Department, School of Engineering and Architecture (EINA), University of Zaragoza \\ María de Luna s/n, Edificio Betancourt, 50018 Zaragoza, SPAIN \\ *Corresponding author: mohamed@unizar.es
}

\begin{abstract}
During the early stages of bone regeneration, oxygen plays a key role, recruiting mesenchymal stem cells and regulating the processes of differentiation, proliferation, and apoptosis. To study in these effects, a 3D computational model has been developed, where the effects of oxygen in the mentioned processes are considered.
\end{abstract}

\section{Introduction}

Oxygen concentration acts as a key stimulus in the regeneration and remodeling of tissues. Processes such as migration, differentiation, proliferation, and apoptosis, being essential for tissue growth, are regulated by the level of oxygen concentration. The living cells need a certain oxygen concentration (normoxia) to continue its needful activities. This level of normoxia differs between different cell types [1]. The lack of oxygen (hypoxia) can carry out the inhibition of vital cell processes [2], and the total lack of oxygen (anoxia), triggers apoptosis.

Here, we present a 3D computational model to study the processes of migration, differentiation, proliferation, and apoptosis, under different oxygen conditions.

\section{Material and methods}

The model has been implemented in the commercial Finite Element software Abaqus, through user element subroutines (UEL), where cells have been discretized with a quasi-spheric geometry formed by 24 cell surface nodes of hexahedral elements (Fig.1).

\section{Cell migration}

Cell forces have been considered under equilibrium in such a way that,

$$
\mathbf{F}_{\text {prot }}+\mathbf{F}_{\text {eff }}+\mathbf{F}_{\text {drag }}=0 \text {. }
$$

Where $\mathbf{F}_{\text {prot }}$ is the protrusion force, $\mathbf{F}_{\text {eff }}$ is the effective traction force, and $\mathbf{F}_{\text {drag }}$ is the drag force.

$\mathbf{F}_{\text {eff }}$ is considered to be driven by the combined effect of the mechanotaxis and chemotaxis cues. It can be calculated by:

$$
\mathbf{F}_{\text {eff }}=\left\|\mathbf{F}_{\text {trac }}\right\| \cdot\left[\mu_{\text {mech }} \frac{\mathbf{F}_{\text {trac }}}{\left\|\mathbf{F}_{\text {trac }}\right\|}+\mu_{o 2} \frac{\nabla\left[o_{2}\right]}{\left\|\nabla\left[o_{2}\right]\right\|}\right] \text {. }
$$

Where $\mathbf{F}_{\text {trac }}$ is the traction force generated by the actin-myosin contraction, $\mu_{\text {mech }}$ and $\mu_{o 2}$ are the effectivity index of the mechanotactic and chemotactic stimulus, respectively. $\nabla\left[o_{2}\right]$ is the gradient of oxygen concentration.

Due to the random polymerization of the actin filaments, a random protrusion force, $\mathbf{F}_{\text {prot }}$, is generated. It can be calculated by,

$$
\mathbf{F}_{\text {prot }}=\kappa \cdot\left\|\mathbf{F}_{\text {trac }}\right\| \cdot \mathbf{e}_{\text {rand }} \text {. }
$$

With $\kappa$, a random factor $(0 \leq \kappa<1)$, and $\mathbf{e}_{\text {rand }}$ is a random directional unit vector.

$\mathbf{F}_{\text {drag }}$, generated by the viscous resistance of the medium, is calculated by,

$$
\mathbf{F}_{\text {drag }}=[6 \cdot \pi \cdot r] \cdot \eta \cdot v
$$

where $[6 \cdot \pi \cdot r]$ is the shape factor for spherical shape, $v$ is the cell velocity, and $\eta$ is the medium viscosity.

\section{Cell fate}

In this model, the oxygen thresholds of normoxia, hypoxia, and anoxia, as well as their effects on different cellular processes, have been defined. Under normoxia, cells can differentiate and proliferate. The cell decision to differentiate into a specific phenotype depends on the mechanical stimulus that the cell receives [3], calculated as:

$$
\gamma(x, t)=\frac{1}{n} \sum_{i=1}^{n} \mathbf{e}_{p o l}: \boldsymbol{\varepsilon}_{i}: \mathbf{e}_{p o l}^{T}
$$

Where $\mathbf{e}_{\text {pol }}$ is the polarization direction, $\boldsymbol{\varepsilon}_{i}$, is the strain tensor at each node of the cell surface, and $n$ is the number of nodes located on the cell surface.

Under hypoxic conditions, cell processes of differentiation and proliferation are inhibited. Finally, under conditions of anoxia, the cells will trigger apoptosis.

\section{Results}

To validate the model, three cases have been evaluated and compared with results reported in the literature [4, 5]. In all cases, initially, 10 mesenchymal stem cells have been seeded in a 
substrate with a rigidity encouraging for osteogenic differentiation $(45 \mathrm{kPa})$.

In the first case, the cells are in a confined substrate, with an initial oxygen concentration of $13 \%$. Cells consume oxygen and undergo through the different thresholds of oxygen. Under normoxia (6-13\% $\left[\mathrm{o}_{2}\right]$ ), cells differentiate and proliferate. Under hypoxia $\left(1-6 \% \quad\left[o_{2}\right]\right)$ cell differentiation or proliferation processes are inhibited. Finally, under anoxia $\left(<1 \%\left[o_{2}\right]\right)$, cells trigger apoptosis. After 40 days, almost all the cells have died, and only one remains in the substrate (Fig.2 (a)).

In the second case, cells are under constant oxygen concentration (21\%). During the whole simulation time, the cells are in normoxic conditions, favoring cell growth. After 40 days, the substrate is full of cells (Fig.2 (b)).

In the third case, an oxygen gradient has been considered along the longitudinal direction, generating zones of normoxia, hypoxia, and anoxia. Thus, cells tend to migrate to normoxia zones. Cells under anoxia thresholds trigger apoptosis, those under hypoxia conditions inhibit cell processes, and those in the normoxic zone differentiate and proliferate. After 40 days, cells have migrated to the zone of maximum oxygen concentration (Fig.2 (c)).

\section{Conclusions}

We have developed a 3D computational model to evaluate the processes of cell migration, differentiation, proliferation, and apoptosis under different oxygen concentrations. It is also capable of qualitatively predicting the cellular response to changes in oxygen concentration. The obtained results are consistent with the bibliography [3, 4]. These results support the idea that oxygen plays a key role in the growth and remodeling of the tissues.

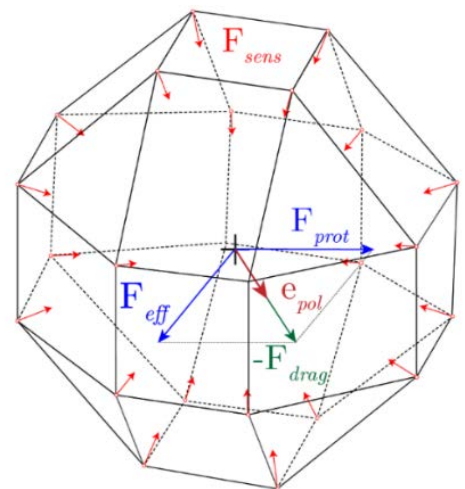

Fig. 1. Cell forces. Sensing forces (red) applied to the cell membrane. Balance of forces acting on the cell, consisting of $\mathrm{F}_{\text {eff }}$ (blue), $\mathrm{F}_{\text {prot }}$ (blue) and $\mathrm{F}_{\text {drag }}$ (green).

\section{ACKNOWLEDGMENTS}

The authors gratefully acknowledge the financial support from the Spanish Ministry of Economy and Competitiveness (MINECO MAT2016-76039-C44-R, AEI/FEDER, UE).

\section{REFERENCIAS}

[1]. SALIM, A., NACAMULI, R.P., MORGAN, E.F., GIACCIA, A.J. and LONGAKER, M.T. Transient changes in oxygen tension inhibit osteogenic differentiation and Runx2 expression in osteoblasts. Journal of Biological Chemistry. 2004, 279 (38). Available from: DOI 10.1074/jbc.M403715200.

[2]. UTTING, J.C., ROBINS, S.P., BRANDAO-BURCH, A, ORRISS, I.R., BEHAR, J. and ARNETT, T.R. Hypoxia inhibits the growth, differentiation and bone-forming capacity of rat osteoblasts. Experimental Cell Research. 2006, 312(10). Available from: DOI 10.1016/j.yexcr.2006.02.007.

[3]. MOUSAVI, S.J. and DOWEIDAR, M.H. Role of mechanical cues in cell differentiation and proliferation: A 3D numerical model. PLoS ONE. 2015, 10(5). Available from: DOI 10.1371/journal.pone.0124529.

[4]. JONITZ, A., LOCHNER, K., LINDNER, T., HANSMANN, D., MARROT, A. and BADER, R. Oxygen consumption, acidification and migration capacity of human primary osteoblasts within a threedimensional tantalum scaffold. Journal of Materials Science: Materials in Medicine. 2011, 22 (9). Available from: DOI 10.1007/s10856-011-4384-6.

[5]. VOLKMER, E., DROSSE, I., OTTO, S., STANGELMAYER, A., STENGELE, M. KALLUKALAM, B.C., MUTSCHLER, W. and SCHIEKER, M.. Hypoxia in Static and Dynamic 3D Culture Systems for Tissue Engineering of Bone. Tissue Engineering Part A. 2008, 14(8). Available from: DOI 10.1089/ten.tea.2007.0231.
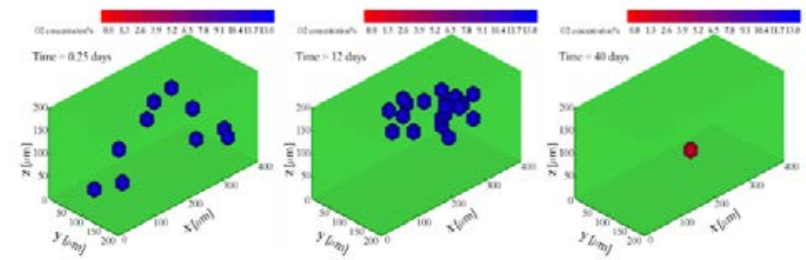

(a)
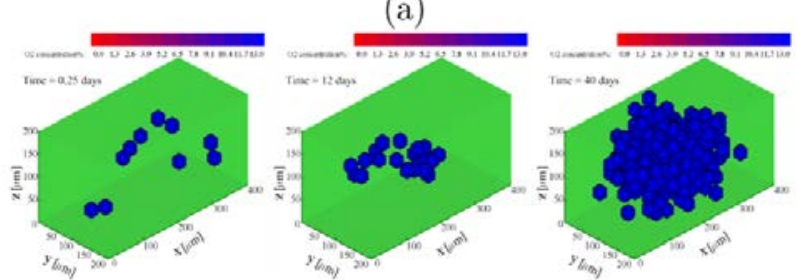

(b)
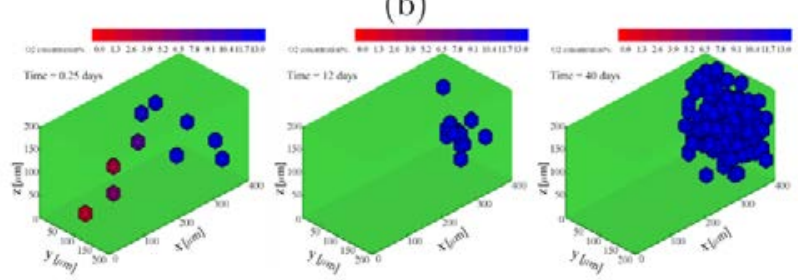

(c)

Fig. 2. Cellular response to different configurations of oxygen concentration, (a) confined cell culture, (b) constant oxygen concentration, and (c) oxygen gradient, along 40 days. 